\title{
Trait Anxiety Mediated by Amygdala Serotonin Transporter in the Common Marmoset
}

\author{
${ }^{\circledR}$ S.K.L. Quah, ${ }^{1,2}$ L. McIver, ${ }^{1,2}{ }^{\circledR}$ A.C. Roberts, ${ }^{1,2 *}$ and ${ }^{\circledR}$ A.M. Santangelo ${ }^{1,2 *}$ \\ ${ }^{1}$ Department of Physiology, Development and Neuroscience, University of Cambridge, Cambridge CB2 3DY, United Kingdom, and ${ }^{2}$ Behavioral and \\ Clinical Neuroscience Institute, University of Cambridge, Cambridge CB2 3EB, United Kingdom
}

High trait anxiety is associated with altered activity across emotion regulation circuitry and a higher risk of developing anxiety disorders and depression. This circuitry is extensively modulated by serotonin. Here, to understand why some people may be more vulnerable to developing affective disorders, we investigated whether serotonin-related gene expression across the brain's emotion regulation circuitry may underlie individual differences in trait anxiety using the common marmoset (Callithrix jacchus, mixed sexes) as a model. First, we assessed the association of region-specific expression of the serotonin transporter (SLC6A4) and serotonin receptor (HTR1A, HTR2A, HTR2C) genes with anxiety-like behavior; and second, we investigated their causal role in two key features of the high trait anxious phenotype: high responsivity to anxiety-provoking stimuli and an exaggerated conditioned threat response. While the expression of the serotonin receptors did not show a significant relationship with anxiety-like behavior in any of the targeted brain regions, serotonin transporter expression, specifically within the right ventrolateral prefrontal cortex (vlPFC) and most strongly in the right amygdala, was associated positively with anxiety-like behavior. The causal relationship between amygdala serotonin levels and an animal's sensitivity to threat was confirmed via direct amygdala infusions of a selective serotonin reuptake inhibitor (SSRI), citalopram. Both anxiety-like behaviors, and conditioned threat-induced responses were reduced by the blockade of serotonin reuptake in the amygdala. Together, these findings provide evidence that high amygdala serotonin transporter expression contributes to the high trait anxious phenotype and suggest that reduction of threat reactivity by SSRIs may be mediated by their actions in the amygdala.

Key words: amygdala; anxiety; emotion; primate; serotonin; transporter

Significance Statement

Findings here contribute to our understanding of how the serotonin system underlies an individual's expression of threat-elicited negative emotions such as anxiety and fear within nonhuman primates. Exploration of serotonergic gene expression across brain regions implicated in emotion regulation revealed that serotonin transporter gene expression in the ventrolateral prefrontal cortex (vlPFC) and most strongly in the amygdala, but none of the serotonin receptor genes, were predictive of interindividual differences in anxiety-like behavior. Targeting of amygdala serotonin reuptake with selective serotonin reuptake inhibitors (SSRIs) confirmed the causal relationship between amygdala serotonin transporter and an animal's sensitivity to threat by reversing expression of two key features of the high trait-like anxiety phenotype: high responsivity to anxiety-provoking uncertain threat and responsivity to certain conditioned threat.

Received Dec. 9, 2019; revised Mar. 6, 2020; accepted Mar. 19, 2020.

Author contributions: S.K.L.Q., A.C.R., and A.M.S. designed research; S.K.L.Q., L.M., A.C.R., and A.M.S.

performed research; S.K.L.Q., A.C.R., and A.M.S. analyzed data; S.K.L.Q., A.C.R., and A.M.S. wrote the paper.

This work was supported by the Medical Research Council (MRC) Program Grant ACR: MR/M023990/1 and performed within the Behavioural and Clinical Neuroscience Institute, University of Cambridge, funded jointly by the Wellcome Trust and MRC. S.K.L.Q. was supported by a scholarship from the Malaysian Public Service Department. We thank Gemma Cockcroft for her help with histology.

The authors declare no competing financial interests.

${ }^{*}$ A.C.R. and A.M.S. are joint senior authors.

Correspondence should be addressed to S.K.L. Quah at sklq2@cam.ac.uk or A.M. Santangelo at as966@ cam.ac.uk.

https://doi.org/10.1523/JNEUROSCI.2930-19.2020

Copyright $\odot 2020$ the authors

\section{Introduction}

Anxiety and fear are adaptive emotions provoked, respectively, by uncertain/distal and certain/proximal threats (Steimer, 2002). However, excessive and uncontrollable anxiety and fear form core symptoms of affective disorders. A greater risk of developing anxiety disorders and depression is associated with high trait anxiety (Jeronimus et al., 2016; Weger and Sandi, 2018), an individual's predisposition to show elevated anxiety and fear (Indovina et al., 2011). Thus, determining the brain mechanisms that underlie trait anxiety provide important insights into why some individuals are at risk of developing anxiety disorders.

Functional neuroimaging studies have revealed alterations in activity within a core circuit involved in the regulation of 
emotion, the prefrontal-cingulate-amygdala circuit, of high trait anxious individuals (Etkin et al., 2011). Specifically, these individuals display increased amygdala reactivity and reduced recruitment of regions of prefrontal cortex (PFC) in response to threatening stimuli (Bishop, 2007; Indovina et al., 2011). Similar dysfunction in this circuitry is associated with anxiety disorders, including altered circuit connectivity (Banks et al., 2007; Prater et al., 2013), hyperactivity in the amygdala (Etkin and Wager, 2007), and hyperactivity and hypoactivity in the prefrontal and cingulate cortex (Shin and Liberzon, 2010).

An important modulator of activity in the prefrontal-cingulate-amygdala circuit is serotonin. The serotonin $1 \mathrm{~A}\left(5-\mathrm{HT}_{1 \mathrm{~A}}\right)$, $2 \mathrm{~A}\left(5-\mathrm{HT}_{2 \mathrm{~A}}\right)$, and $2 \mathrm{C}\left(5-\mathrm{HT}_{2 \mathrm{C}}\right)$ receptors, along with the serotonin transporter, have been implicated in the modulation of threat-related and negative emotion processing (for review, see Deakin, 2013; Fisher and Hariri, 2013; Bocchio et al., 2016). In particular, the serotonin transporter, which is a key regulator of synaptic serotonin, can have a marked impact on activity throughout the emotion-processing circuitry (Canli and Lesch, 2007) and is of particular relevance to our understanding of anxiety disorders. First, the serotonin transporter is the target of selective serotonin reuptake inhibitors (SSRIs), the first line treatment for a number of anxiety disorders (Bandelow et al., 2008; Baldwin et al., 2014). Second, a serotonin transporter gene polymorphism in humans is linked to an individuals' trait anxiety levels (Lesch et al., 1996), altered activity in the prefrontal-cingulate-amygdala circuitry (Pezawas et al., 2005), and SSRI efficacy (Stein et al., 2006). A polymorphism association has also been identified in at least two species of non-human primate, namely rhesus monkeys (Bethea et al., 2004; Kalin et al., 2008) and marmosets (Santangelo et al., 2016).

Although the serotonin system, in general, has been broadly implicated in the expression of threat-driven emotion and trait anxiety, the regionally specific neural mechanisms by which serotonin may contribute to individual differences in trait anxiety remain poorly understood. To address this issue, we investigate alterations in the serotonin system and their causal role in trait anxiety in a non-human primate, the common marmoset. The marmoset's complex behavioral repertoire, relative ease to house, and short period of development before adulthood enables the study of complex behavioral phenotypes while controlling for the influence of environmental factors during development (Oikonomidis et al., 2017). Of particular relevance to the current study is the identification of a trait-like stability in their behavioral reactivity to an anxiety-provoking unknown human (Mikheenko et al., 2015) that is sensitive to anxiolytics (Carey et al., 1992; Santangelo et al., 2016). Furthermore, as the PFC plays a key role in the modulation of the threat circuit, the marked similarity in cortical organization shared between marmosets and humans facilitate translation between species (Shiba et al., 2016; Roberts, 2020).

In experiment 1 , we investigate the relationship between behavioral reactivity to an unknown human and postmortem mRNA expression of the serotonin transporter (SLC6A4) and serotonin 1A (HTR1A), 2A (HTR2A), and 2C (HTR2C) receptors across regions of the emotion regulation circuit including subregions of the PFC, dorsal anterior cingulate cortex (dACC), amygdala, and raphe nuclei. Having identified the strongest predictor of a marmosets' trait anxious behavior, its causal relationship with key characteristics of the trait anxious phenotype were determined by targeted pharmacological manipulations. Specifically, we investigated anxiety-like behavior to uncertainty and the regulation of cued conditioned threat.

\section{Materials and Methods}

\section{Experiment 1}

Animals and study design

All animals were housed at the Innes marmoset colony (Behavioural and Clinical Neuroscience Institute) under controlled temperature $\left(24^{\circ} \mathrm{C}\right)$ and humidity (55\%) conditions, and were maintained on a 12/12 h light/ dark schedule with light transition periods. The animals were housed as male-female pairs (males were vasectomized) and were provided with a balanced diet and water ad libitum.

Experiment 1 consisted of twelve common marmosets (Callithrix jacchus; sex, M/F: 7/5) screened on the human intruder test in early adulthood (age: $3.32 \pm 0.53$ years) to determine levels of anxiety-like behavior. They were a subgroup of 27 animals from Shiba et al. (2014) which had an identical experimental history. Having received aversive discrimination conditioning (over approximately four to five months) followed by a single rubber snake test and the human intruder test, they then received counterbalanced anterior orbitofrontal cortex, OFC-dependent (three to four weeks) and ventrolateral PFC, vlPFC-dependent (three to four weeks) cognitive flexibility tests before being euthanized. Of the remaining 15 animals not included in this study, 13 took part in a prefrontal manipulation study by Agustín-Pavón et al. (2012) and two died unexpectedly during the study and their brains were not obtained. Following completion of this prior study (age: $3.93 \pm 0.68$ years), mRNA from their dissected postmortem brain tissue was quantified in the present study. All procedures were performed in accordance with the project and personal licenses held by the authors under the United Kingdom Animals (Scientific Procedures) Act 1986 and the local Animal Welfare and Ethical Review Body policies. All statistical analyses were conducted with IBM SPSS Statistics (v.25).

\section{Human intruder test}

The test procedure is based on methods by Santangelo et al. (2016), and the animal's behavior was recorded for post hoc test scoring. The animal was first separated into a quadrant of their home-cage for $8 \mathrm{~min}$ (separation phase; Fig. 1A, left panel). Subsequently, an experimenter (unfamiliar to the animal) wearing a realistic latex human mask (Greyland Film) and standard lab attire stood $40 \mathrm{~cm}$ from the cage and maintained eye contact with the animal for $2 \mathrm{~min}$ (intruder phase). Recording continued for a further $5 \mathrm{~min}$ after the intruder left (recovery phase).

Behavioral measurements and vocalizations. Behaviors were scored during the intruder phase and during the final 2 min of the separation phase before the onset of the intruder phase to determine potential effects of the manipulation on the animal's general activity and positioning in the home-cage.

Time spent at the front (TSAF). Percentage TSAF of the cage reflects approach behavior toward the human intruder. For the purposes of scoring, the test quadrant was divided into three zones: front, middle, and back. These different zones represent the depth of the zone relative to the "human intruder."

Time spent at the back. Percentage time spent at the back of the cage reflects avoidance behavior away from the human intruder. Scored similarly to TSAF.

Average height. Average height of the marmoset in the home-cage throughout the test period in centimeters. Positioning high in the cage and closer to the nestbox may reflect the common marmoset's innate flight response upwards as an arboreal species. For scoring purposes, the test quadrant is divided into five different zones: top of the nestbox, high, middle, low, and floor. These different zones represent the height of the zones relative to the bottom of the test quadrant.

Locomotion. Percentage time spent changing locations within the home-cage defined as changing position of all four limbs.

Head and body bobs. Frequency of the animal bobbing its head to the side while staring at the object of interest. This action is often followed with vocalization. Head-bobbing is often observed in the presence of an unfamiliar human and may be an alarm behavior intended to signal potential threats to conspecifics.

Tse-egg calls. A vocalization consisting of a single utterance of tse followed by a single or a series of egg calls. Tse-egg calls are the primary call type uttered during vigilance behavior $(89.2 \%$ and $80.4 \%$ of total 


\section{A Human Intruder test}

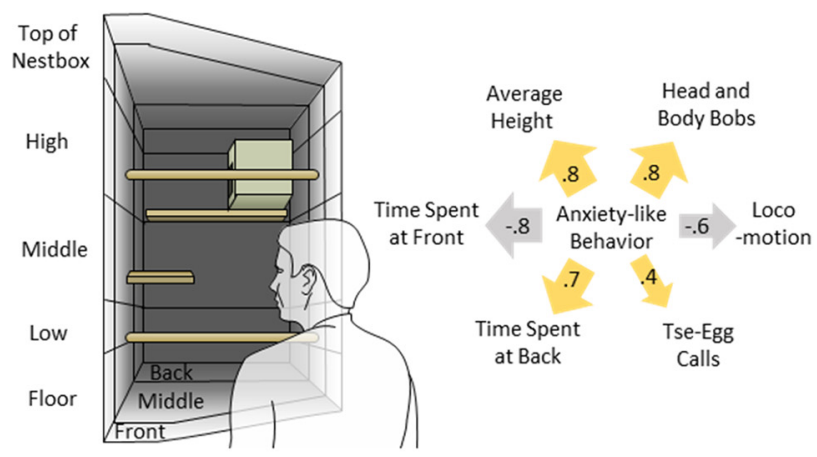

B Target brain region for gene expression analysis



C Conditioned Threat Extinction Paradigm

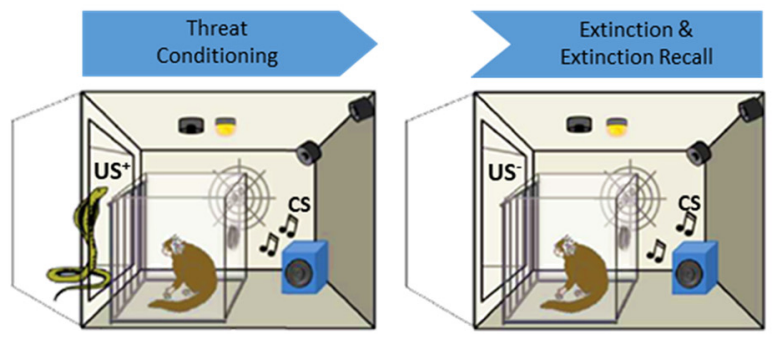

Figure 1. Experimental paradigm. Schematic of $(\boldsymbol{A})$ the human intruder test setup with relevant zones for the measurement of average height, TSAF and back (left panel). Relative contribution of each behavioral measure (reflected by the width of the arrow) to the anxiety factor score is shown in the right panel. Gold arrows represent significant positive-loading measures; gray arrows signify significant negative-loading measures. Positive loadings indicate that higher anxiety correspond to an increase in that specific measure, while a negative loading indicates a decrease. Factor loadings were significant above $|0.4|$ (Stevens, 1992). (B) Schematic depicting brain tissue dissection of the regions of interest (coronal view) (i) anterior/posterior, $\mathrm{AP}=+15.8 \mathrm{~mm}$ : medial PFC, $\mathrm{mPFC}$ (red), vIPFC (yellow), OFC (orange); (ii) $\mathrm{AP}=+13.2 \mathrm{~mm}$ : $\mathrm{dACC}$ (green); (iii) $\mathrm{AP}=+9.6 \mathrm{~mm}$ : amygdala (blue); and (iv) $\mathrm{AP}=$ $+2.0 \mathrm{~mm}$ : DRN (teal) and MRN (purple). (C) In the conditioned threat extinction paradigm, animals were conditioned to the conditioned stimulus, $C S$ associated with the unconditioned stimulus, US $^{+}$(rubber snake) before their extinction and extinction recall of the conditioned response was assessed in the absence of the $\mathrm{US}^{+}$.

calls during vigilance in adults and juveniles, respectively; Bezerra and Souto, 2008).

Behavioral analysis. An overall anxiety score was calculated based on an exploratory factor analysis (EFA) with a principal axis factoring extraction method performed on human intruder data obtained from 171 animals (age: $2.29 \pm 0.62$ years; sex, M/F: 90/81; including the cohort in experiment 1; Quah et al. 2020). The main contributors to this factor's score representing anxiety-like behavior included TSAF and back, average height, locomotion, head and body bobs, and tse-egg calls (Fig. $1 \mathrm{~A}$, right panel). Those animals with the highest score spent the majority of their time toward the back of the cage, high up, remaining relatively still, and making head and body bobs and calls.

Initial runs of the EFA included: TSAF, time spent at the back, average height, locomotion, head and body bobs, tse-egg calls, and other vocalizations. Variables with measure of sampling adequacy below the standard of 0.5 defined by Field (2013) were removed from the EFA. Only one factor was extracted accounting for $39.7 \%$ of the total variance. There were 16 (44.0\%) nonredundant residuals, reflecting the sufficient fit of the one-factor model. The factor with six significantly loading items had moderate reliability, Cronbach's $\alpha=0.64$, a realistic level for psychological constructs (Kline, 2000).

Serotonin transporter and receptor gene expression

Animals in experiment 1 were premedicated with ketamine hydrochloride before being euthanized with pentobarbital sodium (Dolethal; 200 $\mathrm{mg}$ in $1 \mathrm{ml}$; Merial Animal Health). Brain tissue dissection of the regions of interest was guided by neuroanatomical landmarks. Punches were taken from the amygdala, dorsal raphe nucleus (DRN) and medial raphe nucleus (MRN), and cortical regions were dissected, as illustrated in Figure $1 B$. Prefrontal areas were dissected having made a coronal cut at the level of the genu of the corpus callosum. Cuts were made with a razor and A-P positions were guided by a ruler. Total RNA was extracted with the RNeasy Plus Universal Mini kit (QIAGEN). Target gene mRNA was quantified with quantitative reverse transcription polymerase chain reaction (qRT-PCR) using Brilliant II SYBR Green qRT-PCR Master Mix kit, 1-Step (Agilent Technologies) and the CFX96 Touch Real-Time PCR Detection System (Bio-Rad). Details of the primers used are shown in Extended Data Table 2-1. The four marmoset-specific reference genes were selected based on their expression stability in published papers evaluating their use as qRT-PCR reference genes with marmoset brain tissue: $\beta$-Actin (ACTB), TATA-box binding protein (TBP), and glyceraldehyde-3-phosphate dehydrogenase (GAPDH; Shimamoto et al., 2013), and succinate dehydrogenase complex, subunit A (SDHA; Fujii et al., 2013; Shimamoto et al., 2013). All reactions were performed in duplicates (triplicates for inter-run calibrators) at $100 \mathrm{~nm}$ primer concentration.

\section{Statistical analysis}

Correlations between mRNA levels and anxiety scores were calculated with Pearson's correlation. To confirm that there was not a significant issue of multicollinearity, the correlation coefficient of each transcript across all target brain regions was determined to be below 0.8 (Franke, 2010). Family-wise error rate for the exploratory correlations of each target gene were accounted for using the Bonferroni correction against the number of areas (12) with adjusted $\alpha$ level of $\alpha_{a d j}=0.0042$. Effect sizes for significant findings were computed based on Cohen's method (Cohen, 1988, 1992). Differences between correlation coefficients were computed using Fisher's r-to-z transformation and Steiger's equation (Steiger, 1980) with an asymptotic $z$ test (Lee and Preacher, 2013). The potential effects of sex and age at test on the anxiety composite score were determined with an independent samples $t$-test and Pearson's correlation, respectively.

\section{Experiment 2}

Animals and study design

A naive cohort of six marmosets (age: $3.39 \pm 1.28$ years; sex, M/F: $3 / 3$ ) were used in experiment 2 that were chosen as high avoiders of the human intruder (no TSAF of the home-cage) following screening on the human intruder test in early adulthood. Following telemetry and cannulation surgery (described below), animals received saline and citalopram (30 $\mu \mathrm{g} / \mathrm{site}$; Sigma-Aldrich/Tocris) infusions into the amygdala before testing on the human intruder test and conditioned threat extinction paradigm. Despite having shown high avoidance at screening, one animal (animal 6) showed no anxiety-like behavior toward the human intruder subsequently and was excluded from the remainder of the human intruder test sessions. Details of animal test participation are included in Table 1. A lower dose of citalopram $(6 \mu \mathrm{g} / \mu \mathrm{l}$ per site $)$ trialed in the first four marmosets (age: $3.95 \pm 1.42$; sex, M/F: $2 / 2$ ) on the human intruder test produced no significant effect (anxiety score: $t_{(1,3)}=1.10, p=0.35$; average height: $t_{(1,3)}=-0.79, p=0.49$; time spent at front: $t_{(1,3)}=-1.57$, $p=0.22$; time spent at back: $t_{(1,3)}=0.98, p=0.4$; locomotion: $t_{(1,3)}=$ $-0.33, p=0.76$; head and body bobs: $t_{(1,3)}=0.38, p=0.73$; tse-egg calls: 
Table 1. Animal test participation and infusion order in experiment 2

\begin{tabular}{|c|c|c|c|c|c|c|c|}
\hline \multirow{2}{*}{$\frac{\text { Animal }}{1}$} & \multirow{2}{*}{$\frac{\text { Sex }}{F}$} & \multicolumn{4}{|c|}{ Human intruder test } & \multirow{2}{*}{\multicolumn{2}{|c|}{$\begin{array}{l}\text { Conditioned fear extinction } \\
\text { paradigm } \\
\text { Citalopram (30 } \mu \mathrm{g} / \mathrm{site})\end{array}$}} \\
\hline & & \multicolumn{2}{|c|}{ Citalopram (6 $\mu \mathrm{g} / \mathrm{site})$} & \multicolumn{2}{|c|}{ Citalopram (30 $\mu \mathrm{g} / \mathrm{site})$} & & \\
\hline 2 & M & Control & Drug & Control & Drug & Control & Drug \\
\hline 3 & M & Drug & Control & Control & Drug & Drug & Control \\
\hline 4 & $\mathrm{~F}$ & Drug & Control & Drug & Control & Control & Drug \\
\hline
\end{tabular}

Detail of animals' sex and order of test participation in experiment 2. Four animals (subjects 1, 2, 3, and 4) first trialed low-dose citalopram (6 $\mu \mathrm{g} / \mathrm{site}$ ) in the human intruder test. Subsequently, two additional animals joined the study (animals 5 and 6) and all were tested on the high-dose citalopram ( $30 \mu \mathrm{g} / \mathrm{site}$ ) in all tests (human intruder test and conditioned fear extinction paradigm).

$\left.t_{(1,3)}=-0.4, p=0.72\right)$ and was subsequently not used in the final two marmosets.

\section{Surgery}

Telemetry probe surgery. The probe catheter and telemetric blood pressure transmitter (Data Sciences International) were implanted following procedures described previously (Schnell and Wood, 1993).

Cannulation surgery. After at least two weeks of recovery from telemetry surgery, animals underwent bilateral cannulation surgery of the amygdala [15.0-mm-long cannulae, anteroposterior (AP) +9.6, lateromedial $(\mathrm{LM}) \pm 5.6$ ]. Presurgical procedures, surgical monitoring, postoperative care, and protocol for cannulation surgery and postmortem cannulae placement assessment were performed as described previously (Wallis et al., 2017).

\section{Central infusions}

The animal was held gently by an assistant. The drug was infused down the guide cannulae at a rate of $0.5 \mu \mathrm{l} / \mathrm{min}$ for $2 \mathrm{~min}$ (total volume infused: $1 \mu \mathrm{l}$ ) via a sterile injector (Plastics One) connected to a $2-\mu \mathrm{l}$ gastight syringe in a syringe pump with infusion tubing. The injector was left in place for $1 \mathrm{~min}$ before removal to allow for the vehicle/drug to diffuse across the target region. Animals received mock infusions in the weeks before testing. All animals were returned to their home-cage after the infusion and tested $10 \mathrm{~min}$ later. Citalopram hydrobromide was prepared by dissolving the drug in sterile saline. The initial trial of the lower dose of $6 \mu \mathrm{g} / \mu \mathrm{l}$ per site in the amygdala was based on infusions into the much smaller rat amygdala (Inoue et al., 2004). Compared with the higher $30 \mu \mathrm{g} / \mu \mathrm{l}$ per site dose, only the latter had a behavioral effect on the human intruder test, and this higher dose was used for all subsequent dosing.

Postmortem cannulae placement assessment. Animals were premedicated with ketamine hydrochloride $(0.05 \mathrm{ml}$ of a $100-\mathrm{mg}$ solution, i.m.; GE Healthcare and Upjohn) before being euthanized with pentobarbital sodium ( $1 \mathrm{ml}$ of a $200 \mathrm{mg} / \mathrm{ml}$ solution, i.v.; Merial Animal Health). Animals were then perfused transcardially with $0.1 \mathrm{M}$ PBS solution, followed by $4 \%$ paraformaldehyde fixative solution. The brain was left in $4 \%$ paraformaldehyde fixative overnight before being transferred to $30 \%$ sucrose solution for at least $48 \mathrm{~h}$. Brains were then sectioned on a freezing microtome (coronal sections; $60 \mu \mathrm{m}$ ), mounted on slides, and stained with cresyl fast violet for cannula locations to be visualized.

\section{Experiment 2a: pharmacological manipulation on human intruder test}

Animals were tested on the human intruder test as described above. To avoid habituation, different rubber masks were worn for each test. At least two weeks separated each test session, and a counterbalanced design was planned a priori for the order of infusion type.

\section{Data and statistical analysis}

The anxiety score for each session was calculated by first standardizing behavioral scores using the mean and standard deviations of the EFAderived population. The anxiety factor score is the sum of the product of the standardized scores of each contributing variable and the respective factor score coefficients. Differences between group means for the vehicle/drug comparison were calculated using paired samples $t$-tests. The finding that there was no significant difference between repeated control/saline infusions $\left(t_{(4)}=0.72, p=0.51\right)$ indicates that animals did not habituate across repeated test sessions.

\section{Experiment 2b: pharmacological manipulation on conditioned threat extinction paradigm}

Each testing block consisted of five sessions over five consecutive days: two sessions of habituation to the context, a threat conditioning session, an extinction session, and an extinction recall session (Fig. 1C; Wallis et al., 2017). Black and white patterned context panels distinguished individual testing blocks. During habituation sessions, animals received 12, 5 -s duration, US ${ }^{-}$presentations at 110 - to 130 -s intervals, during which an opaque smart glass screen became transparent to reveal an empty chamber. In the threat conditioning session, there were nine trials presented at 160- to 180-s intervals: three trials of CS-US' presentation followed by six trials of CS-US ${ }^{+}$presentation. For the CS-US ${ }^{-}$trials, a 20-s auditory CS $(70 \mathrm{db})$ was presented with the US $^{-}$(illuminated empty chamber) occurring during the last $5 \mathrm{~s}$. For the $\mathrm{CS}_{-} \mathrm{US}^{+}$trials, the animal was exposed to the sight of the rubber snake $\left(\mathrm{US}^{+}\right)$within the illuminated chamber. Infusions took place before the extinction session. During the extinction session, 20 CS-US $^{-}$pairings were presented at 60 to 80 -s intervals. Extinction recall sessions were identical except only 12 CS-US ${ }^{-}$pairings were presented.

All animals received an initial control block with vehicle infusion to evaluate the animal's responsivity to the $\mathrm{US}^{+}$. One animal did not show a behavioral response to the rubber snake and so the initial control block was repeated with the addition of darkness in the test box for the duration of the US presentation. Darkness facilitates fear-like responses in marmosets (Shiba et al., 2017). A counterbalanced design was planned a priori for the order of the type of infusion received: for three of the six animals, the first vehicle session was taken as control, and for the other three animals, an additional vehicle session after drug infusion was taken as control. There were at least two weeks between each testing block.

\section{Behavioral and cardiovascular measures}

During the CS period, the majority of high anxious animals (five out of six) showed rapid head swings (Zeredo et al., 2019), in contrast, one animal maintained a still and hunched body posture akin to freezing. Thus, duration of rapid head swings was the measure of hypervigilant behavior for all of the animals except the animal that froze. For that animal only, hypervigilant behavior was defined as duration of stillness. Blood pressure data collected by the implanted telemetry probe during testing was analyzed using Spike2 (version 8.11; CED) to calculate mean arterial pressure (MAP).

\section{Data analysis}

CS-directed measures, reflecting the animal's conditioned response to the CS, were obtained by subtracting behavioral and cardiovascular scores during the $15 \mathrm{~s}$ immediately before the CS period from the $15 \mathrm{~s}$ during the CS period (before US presentation). Pairs of trials were averaged in the extinction and extinction recall sessions. In the conditioning sessions, the three trials before the introduction of the $\mathrm{US}^{+}$(trials 2-4) were averaged to obtain a preconditioning measure for each CS; trial 1 

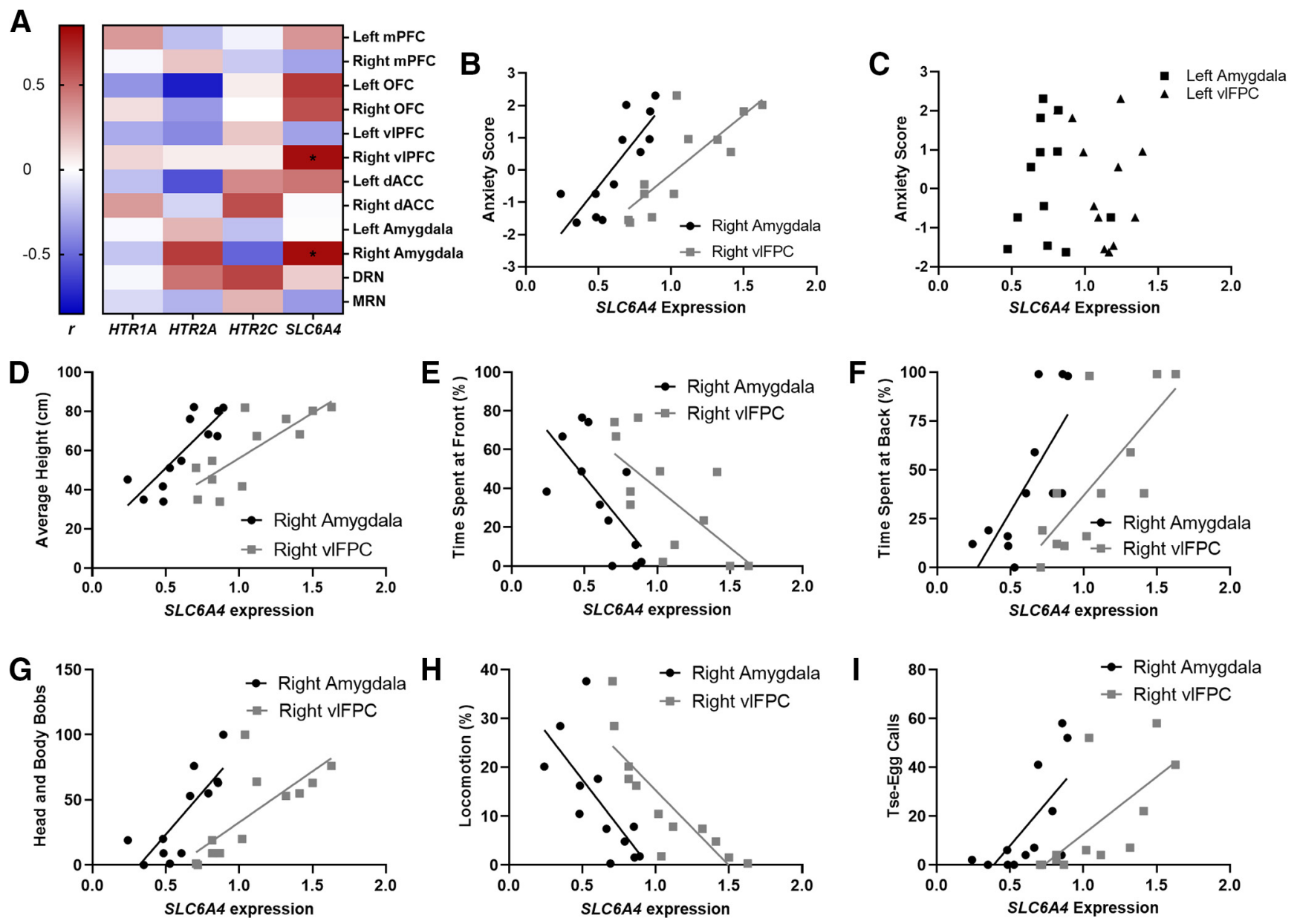

Figure 2. Positive relationship between SLC6A4 mRNA levels in the right amygdala and VIPFC and anxiety-like behavior in the human intruder test. $A$, Heatmap of the correlations between target gene expression in each region of interest and an anxiety-like behavioral score on the human intruder test. Color gradient represents Pearson correlation coefficient, $r .{ }^{*}$, significant correlations, $p_{\text {corr }}<0.05$. Specific values shown in Extended Data Table 2-2. B. Higher anxiety scores were only significantly associated with higher right amygdala and right vIPFC SLC6A4 mRNA $(n=12)$. C, This relationship was not seen in the left amygdala and vIPFC. All the behavioral measures contributing to the factor score were also associated with right amygdala and vIPFC SLC6A4 mRNA levels including $(\boldsymbol{D})$ average height, $(\boldsymbol{E})$ time spent at front, $(\boldsymbol{F})$ time spent at back, $(\boldsymbol{G})$ head and body bobs, $(\boldsymbol{H})$ locomotion, and $(\boldsymbol{I})$ tse-egg calls. Details of primers in Extended Data Table 2-1.

having been excluded due to the animal's initial orienting response to novel CSs. Following introduction of the US ${ }^{+}$, it was noted that some animals showed a rise in MAP during the CS period early on in acquisition but that this declined toward the end of the session, while for others the rise occurred later in the session. To compensate for this variation, acquisition of the conditioned response was calculated as the difference between the CS-directed MAP response before $\mathrm{US}^{+}$introduction and the peak CS-directed MAP response (consecutive pair of CSs) after $\mathrm{US}^{+}$ introduction. Statistical design can be found in the Results for experiment $2 b$.

\section{Results}

Experiment 1: SLC6A4 gene expression in the right amygdala and the right vlPFC correlates positively with anxiety scores Among all targeted genes across the brain regions of interest, only the serotonin transporter gene in the right amygdala and right vlPFC showed a statistically significant relationship with the factor score for anxiety-like behavior after correcting for multiple comparisons. A heatmap of the correlations is shown in Figure $2 A$ and detailed in Extended Data Table 2-2. SLC6A4 mRNA levels in the right amygdala $\left(r=0.809, p_{\text {corr }}<0.05\right)$ and right vlPFC $\left(r=0.806, p_{\text {corr }}<0.05\right)$ were positively correlated with anxiety-like behavior with a large effect size (Fig. $2 B$ ). No such correlation was seen for the left amygdala $(r=0.005$, $p=0.99$; Fig. $2 C)$ and vlPFC ( $r=-0.32, p=0.32$; Fig. $2 C)$, and these differences between the left and right hemisphere were significant (amygdala: $z=2.11, p=0.03$; vlPFC: $z=2.63, p=0.008$ ). The anxiety composite score was not associated with sex $\left(t_{(10)}=\right.$ $-1.4, p=0.20)$ or age at test $(r=0.22, p=0.50)$. Subsequently, we determined whether the significant correlations were driven by a specific subset of the underlying variables of the anxiety-like behavior score. We analyzed the relationship between the right amygdala and right vlPFC SLC6A4 mRNA levels with those behaviors significantly loading on the anxiety score. Greater right amygdala and vlPFC SLC6A4 expression was correlated with greater avoidance as shown by less time at the front (amygdala: $r$ $=-0.69, p=0.014$; vlPFC: $r=-0.68, p=0.015)$, more time at the back (amygdala: $r=0.71, p=0.009$; vlPFC: $r=0.76, p=0.004$ ), and greater height (amygdala: $r=0.86, p<0.001$; vlPFC: $r=0.79$, $p=0.002$ ), and increased vigilance as shown by less time moving around the cage (amygdala: $r=-0.70, p=0.012$; right vlPFC: $r=$ $-0.84, p=0.001$ ), greater number of head and body bobs (amygdala: $r=0.77, p=0.004$; vlPFC: $r=0.74, p=0.006$ ), and tse-egg calls (amygdala: $r=0.66, p=0.02$; vlPFC: $r=0.69, p=0.013$ ) in response to the human intruder $(r>0.5$; Fig. $2 D-I)$. Sex did not contribute to differences in anxiety scores (independent $t$-tests, $p_{\text {corr }}>0.05$ ). 

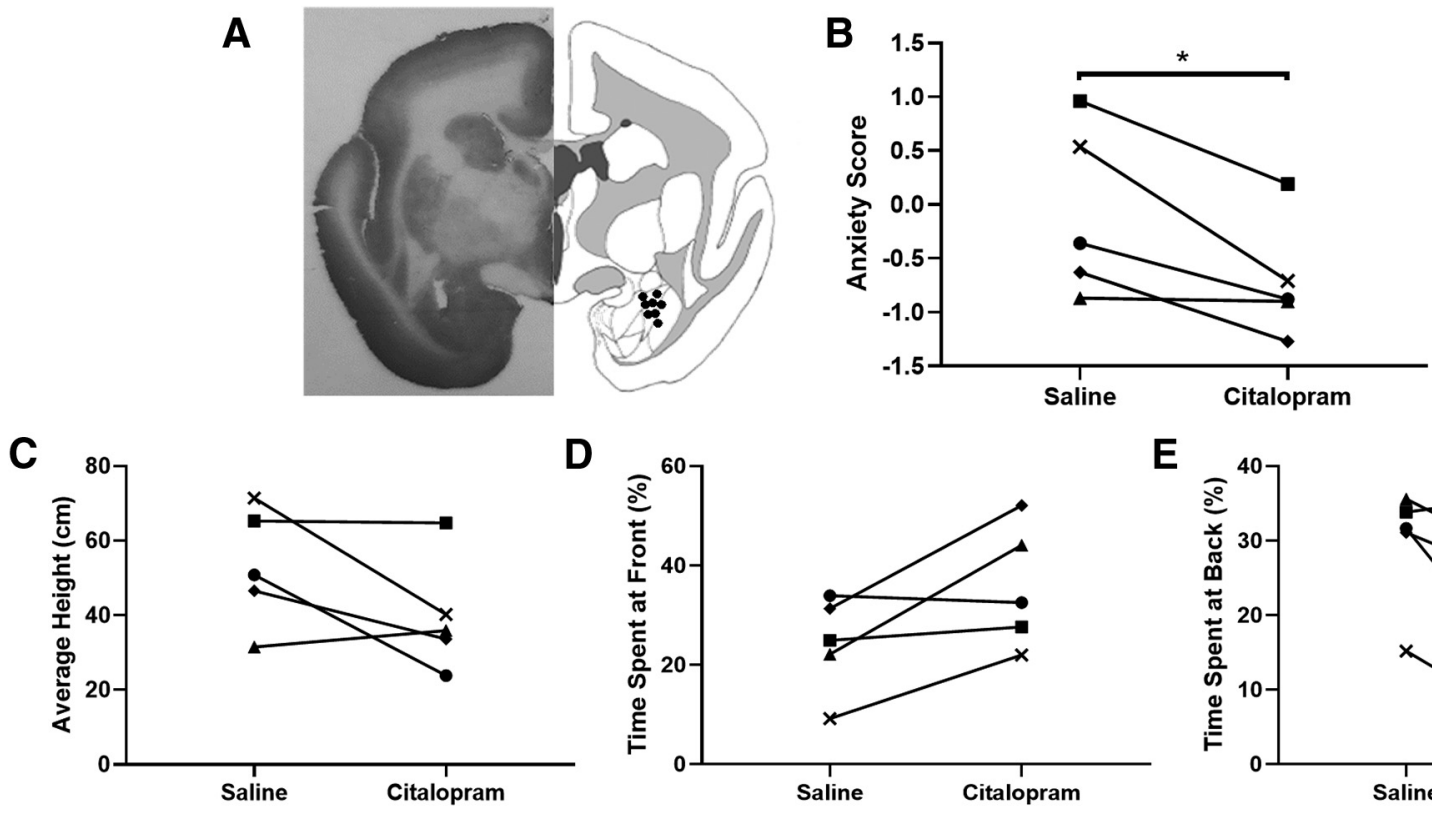

E
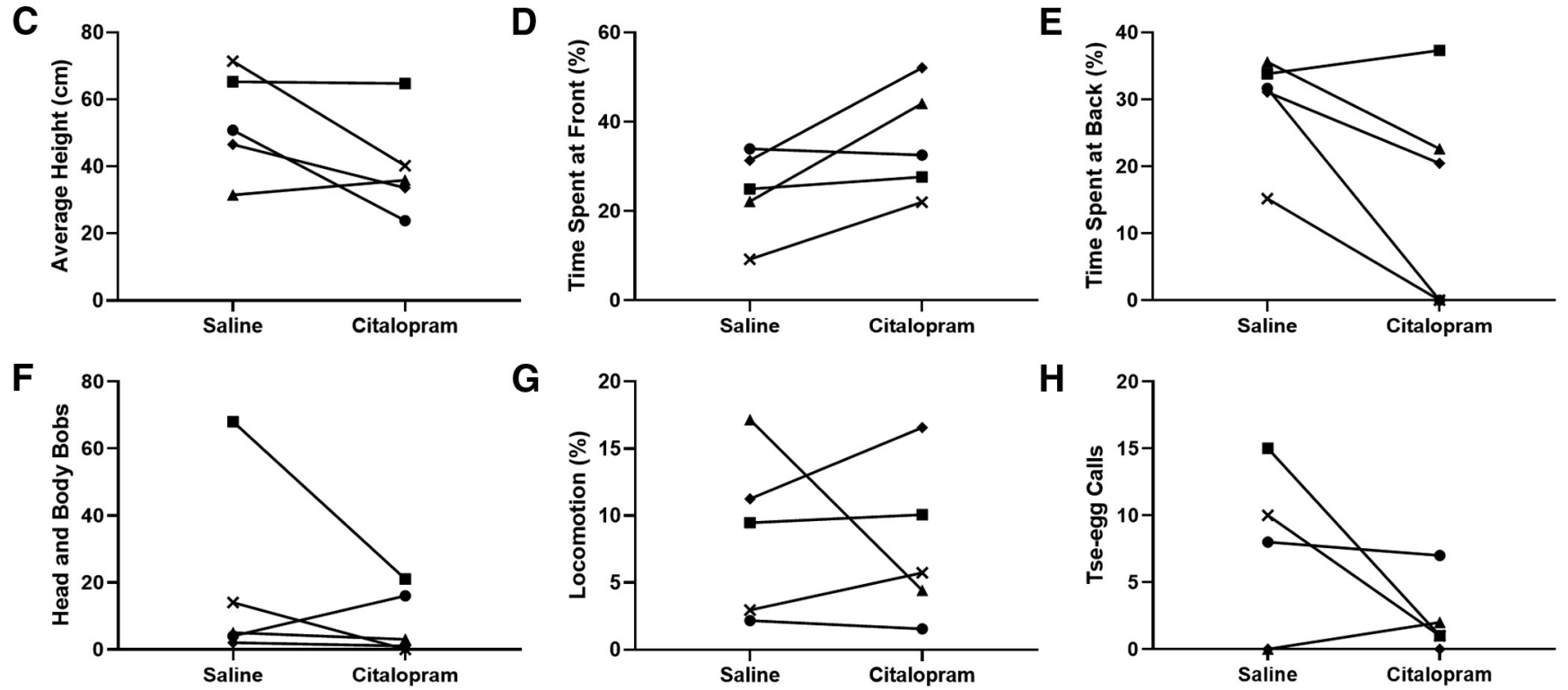

Figure 3. Amygdala serotonin reuptake inhibition reduced anxiety in response to a human intruder. $\boldsymbol{A}$, Representative histologic section (left) and cannulation sites of individual animals (right). Direct infusions of an SSRI (citalopram; $30 \mu \mathrm{g} / \mathrm{site}$ ) into the amygdala resulted in reduction in anxious behavior to a human intruder as measured by the overall anxiety score (B) ( ${ }^{*}$ significant difference, $\left.p<0.05\right)$; but did not consistently affect specific individual behaviors that loaded on the anxiety score, including $(\boldsymbol{C})$ average height, $(\boldsymbol{D})$ time spent at front, $(\boldsymbol{E})$ time spent at back, $(\boldsymbol{F})$ locomotion, $(\boldsymbol{G})$ head and body bobs, and $(\boldsymbol{H})$ tse-egg calls. For example, in response to SSRI infusions, subject 2 showed marked decrease in head and body bobs $(\boldsymbol{G})$ and tse-egg calls $(\boldsymbol{H})$, while subject 1 showed primarily decreased time spent at the back $(\boldsymbol{E})$. Each symbol corresponds to an individual animal ( $n=5$; black circle: subject 1 ; black square: subject 2; black triangle: subject 3; black rhombus: subject 4; black cross: subject 5).

To determine the relative contribution of right vlPFC and amygdala serotonin transporter expression toward a predictive model of an animal's anxiety-like behavior score, a backward stepwise regression was implemented with both right amygdala and vlPFC serotonin transporter expression as predictors in the initial model $\left(F_{(1,10)}=11.9, p=0.003\right)$. The stepwise regression revealed that anxiety-like behavior scores were best predicted with a model with just the right amygdala expression $\left(F_{(1,10)}=18.9\right.$, $p=0.001$ ) and that vlPFC expression did not contribute uniquely to the overall model.

Experiment 2a: blockade of amygdala serotonin reuptake has an overall anxiolytic effect as measured by the anxiety score on the human intruder test

Given that experiment 1 revealed that transporter levels in the amygdala were the best predictor of anxiety-like behavior, we focused on the amygdala, rather than vlPFC, serotonin transporter in experiment 2 . We hypothesized that local blockade of amygdala serotonin transporter with an SSRI (see Fig. $3 A$, infusion placement) would reduce anxiety-like behavior in the human intruder test. Although the results in experiment 1 highlighted the right amygdala, the amygdala was targeted bilaterally to avoid confounds arising from individual differences in hemispheric asymmetries (for more details, see Discussion).
As predicted, local infusion of a high dose of citalopram significantly reduced anxiety-like behavior as measured by the anxiety factor score in the human intruder test $t_{(4)}=3.3, p=0.031$, $d=1.45, n=5$; Fig. $3 B$ ). No one particular variable however contributed significantly to this effect (average height: $t_{(4)}=1.9$, $p=0.127$; time spent at front: $t_{(4)}=-2.4, p=0.073$; time spent at back: $t_{(4)}=2.39, p=0.076$; locomotion: $t_{(4)}=0.3, p=0.78$; head and body bobs: $t_{(4)}=1.03, p=0.36$; and tse-egg calls: $t_{(4)}=1.45$, $p=0.22$ ), indicating that amygdala serotonin transporter blockade primarily affected the overall composite anxiety score (Fig. $3 \mathrm{C}-\mathrm{H})$. The manipulation did not have a consistent effect on general locomotor activity and positioning in the cage during the separation phase before the entrance of the human intruder (average height: $t_{(1,4)}=0.54, p=0.62$; time spent at front: $t_{(1,4)}=2.06$, $p=0.11$; time spent at back: $t_{(1,4)}=0.65, p=0.55$; locomotion: $\left.t_{(1,4)}=-1.74, p=0.16\right)$.

Experiment 2b: blockade of amygdala serotonin reuptake during extinction reduced behavioral and physiological expression of conditioned threat

All animals tested on the conditioned threat extinction paradigm showed a $\mathrm{US}^{+}$-directed increase in MAP during the threat conditioning session (before the extinction session when the manipulation was conducted), indicating that the threat had an 


\section{A}

\section{Cardiovascular response to US ${ }^{+}$}

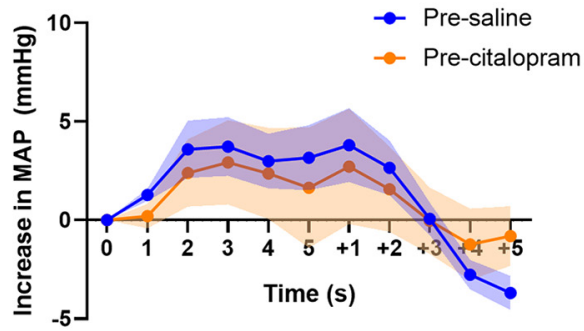

B

Conditioning

Extinction

Extinction Recall

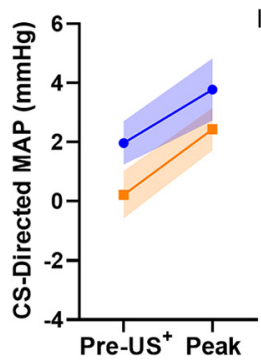

Infusion

*

- Saline

- Citalopram

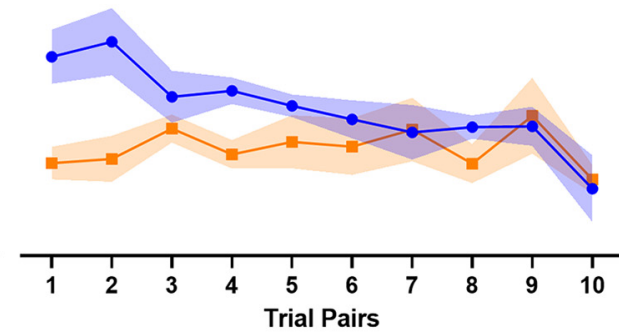

Extinction

C Conditioning

Extin



Infusion

*

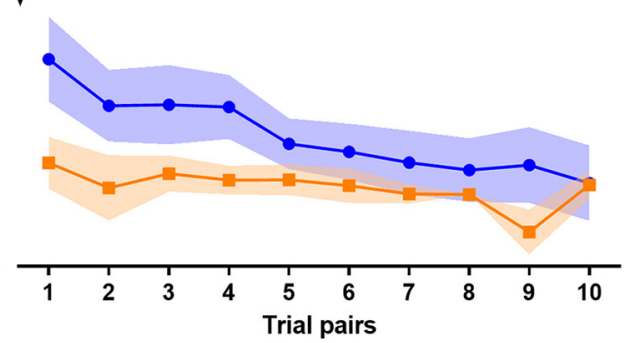

Extinction Recall

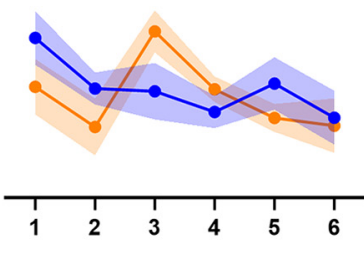

- Saline

- Citalopram

Figure 4. Amygdala serotonin reuptake inhibition reduced physiological and behavioral expression of conditioned threat. $A$, During acquisition of threat conditioning, animals $(n=6)$ showed a robust elevation in cardiovascular response (MAP) to $\mathrm{US}^{+}$presentation. Values are expressed as the increase in MAP relative to the average MAP of the $5 \mathrm{~s}$ before US ${ }^{+}$onset. Data are shown from $\mathrm{US}^{+}$onset $(0-5 \mathrm{~s})$, and $5 \mathrm{~s}$ after its termination $(+1$ to $+5 \mathrm{~s})$. Graphs show the change in (S-directed $(\boldsymbol{B})$ MAP and $(\boldsymbol{C})$ hypervigilant behavior of bilateral saline (blue) and citalopram (orange; $30 \mu \mathrm{g} / \mathrm{site}$ ) blocks across trials for conditioning, extinction, and extinction recall sessions (shading indicates SEM). During conditioning, animals showed significant peak CS-directed MAP and hypervigilant behavior with no differences in conditioning between blocks (left graphs). During extinction, amygdala serotonin reuptake inhibition significantly reduced the expression of CS-directed MAP and CS-directed hypervigilant behavior across trial pairs (middle graphs; ${ }^{*}$ significant effects of manipulation and trial, and significant interaction between the effects of both, $p<.05)$. On extinction recall session, (S-directed MAP and hypervigilant behavior generally declined over trial pairs but there was no effect of manipulation or interaction (right graphs).

arousing effect (Fig. 4A). They also displayed a rise in their CSdirected hypervigilant behavioral and cardiovascular response after $\mathrm{US}^{+}$exposure, indicating conditioning (Fig. 4B,C, left graphs). A multilevel model, accounting for the random effect of individual animals, with factors of manipulation and time showed that the increase in MAP across the $\mathrm{US}^{+}$period (time: $\left.F_{(1,33.9)}=6.27, p=0.017\right)$ did not differ between subsequent vehicle and SSRI manipulations (manipulation: $F_{(1,16.6)}=1.23$, $p=0.28$; manipulation $\times$ time interaction: $F<1$ ). A similar multi-level model with factors of manipulation and trial pair, showed a rise in both their peak CS-directed hypervigilant behavior $\left(F_{(1,20.8)}=4.46, p=0.047\right)$ and cardiovascular response (MAP: $\left.F_{(1,21.54)}=6.93, p=0.015\right)$ in trials post $\mathrm{US}^{+}$exposure (Fig. 4B,C, left graphs). There was a trend for a difference between subsequent vehicle and SSRI manipulations in the CSdirected MAP response $\left(F_{(1,21.54)}=4.07, p=0.056\right)$, regardless of whether it was pre-conditioning or post-conditioning, but no difference in CS-directed hypervigilant behavior $(F<1)$. Furthermore, the interaction between conditioning i.e., trial pairs before and after exposure to the US ${ }^{+}$, and subsequent manipulation was not significant, indicating that animals' conditioning did not differ between animals going on to receive vehicle or SSRI in extinction (both CS-directed MAP and hypervigilant behavior, manipulation $\times$ trial pairs interaction: $F<1$; Fig. $4 B, C$, left graphs). Similarly, during the baseline period (BL, immediately before the CS period), MAP and hypervigilant behavior did not differ after US ${ }^{+}$exposure (BL MAP: $F_{(1,16.7)}=1.4, p=0.25$; BL hypervigilance: $F<1$ ) and were not affected by the manipulation ( $F<1$; Fig. $5 A, B$, left graphs). The interaction between conditioning in BL was also not significant $(F<1)$.

During extinction, expression of both CS-directed hypervigilant behavior and MAP were significantly reduced by amygdala serotonin reuptake inhibition ( $p<0.05$; Fig. $4 B, C$, middle graphs). Compared with saline, amygdala serotonin blockade reduced CSdirected MAP (manipulation $\times$ trial pairs interaction: $F_{(1,56.3)}=$ $6.25, p=0.015$; manipulation: $F_{(1,63.5)}=23.35, p<0.001$; trial pairs: $F_{(1,56.3)}=15.83, p<0.001$ ) and hypervigilant behavior (manipulation $\times$ trial pairs interaction: $F_{(1,53.1)}=4.24, p=0.044$; mani- 
A

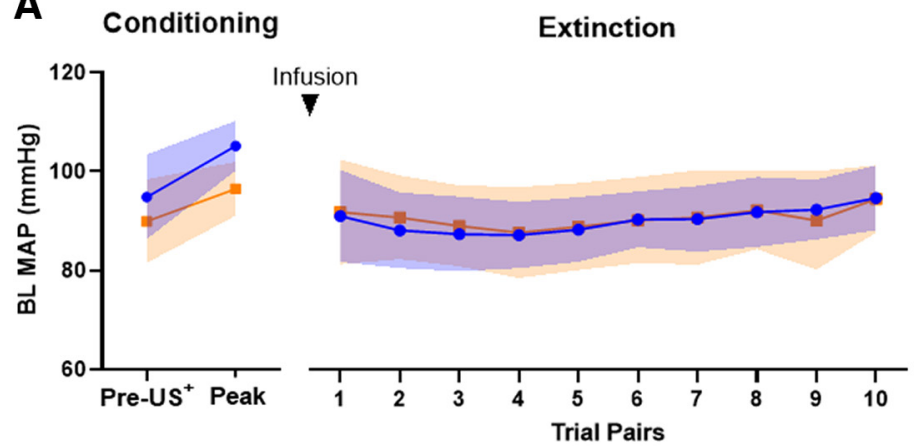

B Conditioning

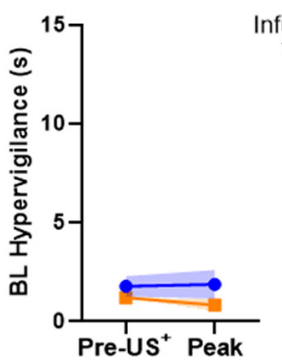

Extinction

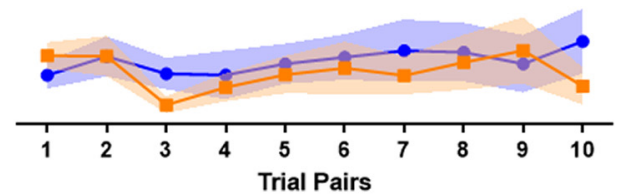

Extinction Recall

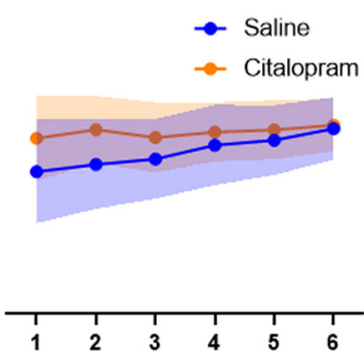

Extinction Recall

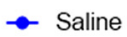

$\rightarrow$ Citalopram

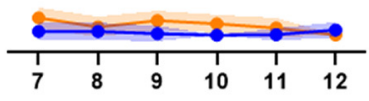

Figure 5. BL MAP and behavioral hypervigilance in the conditioned threat extinction paradigm was not affected by blockade of amygdala serotonin reuptake. During the acquisition session (left graphs), BL (A) MAP and (B) hypervigilance did not differ after exposure to the US ${ }^{+}$and between testing block. Blockade of amygdala serotonin reuptake before the extinction session did not affect BL $(\boldsymbol{A})$ MAP and $(\boldsymbol{B})$ hypervigilant response during the extinction session (middle graphs) and the extinction recall session (right graphs) the day after (shading indicates SEM).

pulation: $F_{(1,52.8)}=12.51, p=0.001$; trial pairs: $F_{(1,53.1)}=13.5, p=$ 0.001 ) from the beginning of the extinction session, indicating reduced responsivity to the conditioned threat stimulus (Fig. $4 B, C$, middle graphs). MAP and hypervigilant behavior during the $\mathrm{BL}$ period in the extinction session was not affected by the manipulation, nor did they change significantly across trial pairs (MAP: manipulation, trial pairs, and manipulation $\times$ trial pairs interaction: $F<1$; hypervigilance: manipulation and trial pairs: $F<1$; manipulation $\times$ trial pairs interaction: $F_{(1,53.2)}=1.46, p=0.23$; Fig. $5 A, B$, middle graphs).

On the extinction recall session, CS-directed $\operatorname{MAP}\left(F_{(1,41.0)}=\right.$ 5.46, $p=0.024)$ and hypervigilant behavior $\left(F_{(1,39.7)}=6.76\right.$, $p=0.013$ ) generally declined over the session, but there was no effect of manipulation from the previous day's extinction session on either CS-directed MAP (manipulation, and manipulation $\times$ trial pairs interaction: $F<1$; Fig. $4 B$, right graph) or CS-directed hypervigilant behavior (manipulation, and manipulation $\times$ trial pairs interaction: $F<1$; Fig. $4 C$, right graph). Similar to the extinction session, BL measures of MAP and hypervigilant behavior in the extinction recall session was not affected by the manipulation from the day before and was not affected across trial pairs (MAP: manipulation, trial pairs, and manipulation $\times$ trial pairs interaction: $F<1$; hypervigilance: manipulation: $F_{(1,37.8)}=$ 3.19, $p=0.082$; trial pairs: $F_{(1,42.0)}=2.44, p=0.13$; manipulation $\times$ trial pairs interaction: $F_{(1,42.0)}=1.90, p=0.18$; Fig. $5 A, B$, right graphs).

\section{Discussion}

Although the serotonergic system has been implicated in threatrelated responses, a region-specific causal link between the expression of key serotonergic components and individual differences in trait anxiety is unknown. Here, in a nonhuman primate model, we reveal a positive association between post-mortem serotonin transporter mRNA expression levels in the right vlPFC and most strongly in the amygdala, and individual variation in reactivity to uncertain threat, as measured by the human intruder test. Specifically, high levels of serotonin transporter mRNA in these regions were associated with heightened anxietylike responses. This relationship appeared both region and gene specific, since it was not found in other frontal areas assessed, namely, the OFC, mPFC, and dACC or the raphe nuclei, or for the serotonergic receptor genes, HTR1A, HTR2A, and HTR2C. Importantly, we also demonstrate that acute inhibition of the amygdala serotonin transporter was able to ameliorate high anxiety-like behavior and reduce the expression of cued conditioned threat responses in animals that had been screened to show high avoidance of the human intruder. Taken together, the combined approach of postmortem cross-regional gene expression analysis and targeted intervention demonstrate a causal mechanism for region-specific changes in the genetic expression of the serotonin transporter gene underlying individual expression of the high trait-like anxiety phenotype in non-human primates.

The finding that lower SLC6A4 mRNA in the amygdala is associated with lower anxiety-like behavioral scores is consistent with the anxiolytic effect of chronic SSRIs (Bandelow et al., 2008) and suggests that high amygdala-specific serotonin transporter expression may play a role in an individual's vulnerability to anxiety. This hypothesis is supported by our prior correlative finding of lower extracellular serotonin in response to an SSRI in the amygdala of high-anxious marmosets (Mikheenko et al., 2015) and is consistent with high amygdala serotonin transporter availability (and thus, likely lower serotonin levels) in high trait anxious rhesus monkeys (Oler et al., 2009) as measured by positron emission tomography (PET). PET studies in humans have been less consistent though, with studies reporting a negative association between serotonin transporter binding and amygdala reactivity in healthy male participants (Rhodes et al., 2007), and both increased 
and decreased serotonin transporter binding in depressed patients (Cannon et al., 2007; Meyer, 2007). Moreover, increased SLC6A4 promoter methylation was associated with decreased human amygdala SLC6A4 mRNA expression and increased threat-related amygdala reactivity (Nikolova et al., 2014).

In contrast to these earlier studies that focused on the serotonin transporter, the present investigation also measured the mRNA expressions levels of serotonin receptor subtypes 1A, 2A, and $2 \mathrm{C}$ and revealed the relatively selective relationship between trait-like anxiety and SLC6A4 mRNA. This may reflect the serotonin transporter's greater role in modulating local serotonin signaling compared with the more limited role of serotonin receptors in regulating their respective downstream pathways. However, the relatively small sample size here may have restricted the ability to detect relationships beyond those with relatively large effect sizes. Thus, subsequent work with an expanded cohort will enable the detection of relationships with more modest effect sizes and aid in determining the specificity of the findings here.

Although increased SLC6A4 mRNA specifically in the right amygdala was the best predictor of trait-like anxiety in marmosets, there was also a positive association with SLC6A4 mRNA in the right vlPFC. The finding that in both cases the effects were lateralized is consistent with studies reporting hemispheric asymmetry of emotion function in humans. However, whether effects are seen in the right (as shown here) or the left vary, a likely consequence of a variety of factors including valence, sex, and region (Wager et al., 2003). The vlPFC has been implicated in the topdown regulation of threat-related attention (Bishop et al., 2004), and reduced activation in the vlPFC is observed in patients with social anxiety disorder (Yokoyama et al., 2015). Moreover, excitotoxic lesions of vlPFC in marmosets heightens threat-related responses (Agustín-Pavón et al., 2012). However, future intervention studies selectively targeting this region will be necessary to elucidate the causal impact of altering serotonin transporter function within the vlPFC on trait anxiety.

The SLC6A4 mRNA measured here, in the amygdala, vlPFC, and other serotonergic projection areas may represent mRNA localized in the neuron terminals or astrocytes (Hirst et al., 1998). The localization of mRNA and ribosomes to presynaptic nerve terminals has been postulated to enable local translation of synaptic proteins beyond the cell body and to be involved in neural plasticity (Akins et al., 2009; Younts et al., 2016). Since our results showed that anxious behavior correlated with SLC6A4 mRNA in the amygdala and vlPFC but not the region of the raphe nuclei where the serotonergic cell bodies reside, this suggests locally regulated SLC6A4 translation within the presynaptic nerve terminals or astrocytes as a potential mechanism modulating serotonin reuptake and consequently anxious behavior.

In the present study, evidence for the causal role of increases in amygdala serotonin transporter in marmosets with high trait-like anxiety was provided in experiment 2 , which investigated the effects of SSRI infusion into the amygdala on behavioral and physiological responses to certain and uncertain threat. Specifically, acute blockade of the amygdala serotonin transporter with citalopram reduced the anxiety score of high anxious animals in response to an unknown human. Unlike that observed with respect to mRNA expression in experiment 1 , however, the manipulation did not affect the individual measures loading on the overall anxiety-like behavioral score; likely due to the marked individual variation in the specific behaviors observed among animals. SSRI infusions into the amygdala also reduced behavioral and physiological expression of conditioned threat in marmosets. Although previous studies have reported decreased freezing in response to contextual conditioned threat (Inoue et al., 2004; Kitaichi et al., 2014) following SSRI infusions into the rat amygdala, any relationship with individual differences in threat reactivity and trait-like behavior, as described here, had not been established. A limitation here, however, is that the neurochemical effects of amygdala citalopram infusions were not measured and so the effect's selectivity on extracellular serotonin cannot be ascertained.

As serotonin in the basolateral amygdala (BLA; the primary subnuclei encompassed by our dissection) evokes depolarization of GABAergic interneurons and indirectly downregulates BLA principal neuron activity (Rainnie, 1999), higher serotonin transporter levels, as shown here, may lead to less sustained downregulation of BLA output by increasing reuptake of amygdala extracellular serotonin. This may provide an underlying mechanism by which amygdala reactivity is increased in high trait anxious individuals (Indovina et al., 2011) and patients with anxiety disorder (Etkin and Wager, 2007). Reduced amygdala downregulation due to trait differences in serotonin neurotransmission may lead to the exaggerated engagement of the threat circuitry and resulting dysregulated threat processing in individuals suffering from excessive anxiety.

Although SSRIs are the first line drug treatment for most instances of anxiety disorders, acute usage of the drug systemically is associated with an exacerbation of anxiety (Sinclair et al., 2009) and enhancement of fear acquisition (Burghardt et al., 2004). Taken together with the contrasting findings here of SSRI's acute anxiolytic and conditioned threat-reducing effect when administered directly into the amygdala, SSRIs may have conflicting effects in different brain regions that lead to a net anxiogenic effect when administered systemically. However, the direction of the acute effects of systemic SSRI can also be, in part, dependent on the genetic background, since systemic SSRI induced an anxiolytic or anxiogenic effect in marmosets depending on whether they carried the high or low expressing allele of a serotonin transporter polymorphism (Santangelo et al., 2016).

In summary, exploratory analysis of postmortem serotonergic gene expression revealed that serotonin transporter gene expression specifically in the vlPFC and most strongly in the amygdala, but not serotonin receptor gene expression across cortical and subcortical brain regions of interest, was associated with interindividual differences in anxiety-like behavior. Targeted intervention demonstrated that inhibition of amygdala serotonin transporter leads to reduction in key threat-processing characteristics of the trait anxious phenotype: anxiety-like behavior and conditioned threat expression. Together, this combined approach provides evidence that amygdala-specific alteration in the serotonin transporter's SLC6A4 mRNA expression may serve as a causal mechanism for an individual's vulnerability to threat-elicited negative affect. Contrary to the anxiogenic effect of acute systemic SSRIs, it has been demonstrated here that an acute SSRI has an anxiolytic effect when infused in the amygdala. This suggests that the chronic anxiolytic effect of SSRIs as an effective antidepressant may be due, in part, to its effects in the amygdala. Further research exploring the cellular underpinnings of serotonin's modulation of amygdala function and its relationship with other nodes in the circuit, including the vlPFC, that may predispose individuals to high trait anxiety are critical steps toward the development of more effective targeted interventions for anxiety, depression, and other mood disorders. 


\section{References}

Agustín-Pavón C, Braesicke K, Shiba Y, Santangelo AM, Mikheenko Y, Cockroft G, Asma F, Clarke H, Man MS, Roberts AC (2012) Lesions of ventrolateral prefrontal or anterior orbitofrontal cortex in primates heighten negative emotion. Biol Psychiatry 72:266-272.

Akins MR, Berk-Rauch HE, Fallon JR (2009) Presynaptic translation: stepping out of the postsynaptic shadow. Front Neural Circuits 3:17.

Baldwin DS, Anderson IM, Nutt DJ, Allgulander C, Bandelow B, Den Boer JA, Christmas DM, Davies S, Fineberg N, Lidbetter N, Malizia A, McCrone P, Nabarro D, O’Neill C, Scott J, Van Der Wee N, Wittchen HU (2014) Evidence-based pharmacological treatment of anxiety disorders, post-traumatic stress disorder and obsessive-compulsive disorder: a revision of the 2005 guidelines from the British Association for Psychopharmacology. J Psychopharmacol 28:403-439.

Bandelow B, Zohar J, Hollander E, Kasper S, Möller HJ, Zohar J, Hollander E, Kasper S, Möller HJ, Bandelow B, Allgulander C, Ayuso-Gutierrez J, Baldwin DS, Buenvicius R, Cassano G, Fineberg N, Gabriels L, Hindmarch I, Kaiya H, Klein DF, et al. (2008) World Federation of Societies of Biological Psychiatry (WFSBP) guidelines for the pharmacological treatment of anxiety, obsessive-compulsive and post-traumatic stress disorders - first revision. World J Biol Psychiatry 9:248-312.

Banks SJ, Eddy KT, Angstadt M, Nathan PJ, Phan KL (2007) Amygdala-frontal connectivity during emotion regulation. Soc Cogn Affect Neurosci 2:303-312.

Bethea CL, Streicher JM, Coleman K, Pau FKY, Moessner R, Cameron JL (2004) Anxious behavior and fenfluramine-induced prolactin secretion in young rhesus macaques with different alleles of the serotonin reuptake transporter polymorphism (5HTTLPR). Behav Genet 34:295-307.

Bezerra BM, Souto A (2008) Structure and usage of the vocal repertoire of Callithrix jacchus. Int J Primatol 29:671-701.

Bishop SJ (2007) Neurocognitive mechanisms of anxiety: an integrative account. Trends Cogn Sci 11:307-316.

Bishop S, Duncan J, Brett M, Lawrence AD (2004) Prefrontal cortical function and anxiety: controlling attention to threat-related stimuli. Nat Neurosci 7:184-188.

Bocchio M, McHugh SB, Bannerman DM, Sharp T, Capogna M (2016) Serotonin, amygdala and fear: assembling the puzzle. Front Neural Circuits 10:24.

Burghardt NS, Sullivan GM, McEwen BS, Gorman JM, LeDoux JE (2004) The selective serotonin reuptake inhibitor citalopram increases fear after acute treatment but reduces fear with chronic treatment: a comparison with tianeptine. Biol Psychiatry 55:1171-1178.

Canli T, Lesch K-P (2007) Long story short: the serotonin transporter in emotion regulation and social cognition. Nat Neurosci 10:1103-1109.

Cannon DM, Ichise M, Rollis D, Klaver JM, Gandhi SK, Charney DS, Manji HK, Drevets WC (2007) Elevated serotonin transporter binding in major depressive disorder assessed using positron emission tomography and [11C]DASB; comparison with bipolar disorder. Biol Psychiatry 62:870877.

Carey GJ, Costall B, Domeney AM, Jones DN, Naylor RJ (1992) Behavioural effects of anxiogenic agents in the common marmoset. Pharmacol Biochem Behav 42:143-153.

Cohen J (1988) Statistical power analysis for the behavioral sciences. Hillsdale: Lawrence Erlbaum Associates.

Cohen J (1992) A power primer. Psychol Bull 112:155-159.

Deakin JFW (2013) The origins of " 5 -HT and mechanisms of defence" by Deakin and Graeff: a personal perspective. J Psychopharmacol 27:10841089.

Etkin A, Wager TD (2007) Functional neuroimaging of anxiety: a meta-analysis of emotional processing in PTSD, social anxiety disorder, and specific phobia. Am J Psychiatry 164:1476-1488.

Etkin A, Egner T, Kalisch R (2011) Emotional processing in anterior cingulate and medial prefrontal cortex. Trends Cogn Sci 15:85-93.

Field A (2013) Discovering statistics using IBM SPSS statistics. Thousand Oaks: SAGE.

Fisher PM, Hariri AR (2013) Identifying serotonergic mechanisms underlying the corticolimbic response to threat in humans. Philos Trans R Soc Lond B Biol Sci 368:20120192.

Franke GR (2010) Multicollinearity. In: Wiley International Encyclopedia of Marketing. Hoboken: John Wiley \& Sons.

Fujii Y, Kitaura K, Matsutani T, Shirai K, Suzuki S, Takasaki T, Kumagai K, Kametani Y, Shiina T, Takabayashi S, Katoh H, Hamada Y, Kurane I,
Suzuki R (2013) Immune-related gene expression profile in laboratory common marmosets assessed by an accurate quantitative real-time PCR using selected reference genes. PLoS One 8:e56296.

Hirst W, Price G, Rattray M, Wilkin G (1998) Serotonin transporters in adult rat brain astrocytes revealed by $[3 \mathrm{H}] 5$-HT uptake into glial plasmalemmal vesicles. Neurochem Int 33:11-22.

Indovina I, Robbins TW, Núñez-Elizalde AO, Dunn BD, Bishop SJ (2011) Fear-conditioning mechanisms associated with trait vulnerability to anxiety in humans. Neuron 69:563-571.

Inoue T, Li XB, Abekawa T, Kitaichi Y, Izumi T, Nakagawa S, Koyama T (2004) Selective serotonin reuptake inhibitor reduces conditioned fear through its effect in the amygdala. Eur J Pharmacol 497:311-316.

Jeronimus BF, Kotov R, Riese H, Ormel J (2016) Neuroticism's prospective association with mental disorders halves after adjustment for baseline symptoms and psychiatric history, but the adjusted association hardly decays with time: a meta-analysis on 59 longitudinal/prospective studies with 443313 participants. Psychol Med 46:2883-2906.

Kalin NH, Shelton SE, Fox AS, Rogers J, Oakes TR, Davidson RJ (2008) The serotonin transporter genotype is associated with intermediate brain phenotypes that depend on the context of eliciting stressor. Mol Psychiatry 13:1021-1027.

Kitaichi Y, Inoue T, Nakagawa S, Omiya Y, Song N, An Y, Chen C, Kusumi I, Koyama T (2014) Local infusion of citalopram into the basolateral amygdala decreased conditioned fear of rats through increasing extracellular serotonin levels. Prog Neuropsychopharmacol Biol Psychiatry 54:216-222.

Kline P (2000) The handbook of psychological testing. Abingdon: Routledge.

Lee IA, Preacher KJ (2013) Calculation for the test of the difference between two dependent correlations with one variable in common [Computer software]. Available at http://quantpsy.org.

Lesch KP, Bengel D, Heils A, Sabol SZ, Greenberg BD, Petri S, Benjamin J, Müller CR, Hamer DH, Murphy DL (1996) Association of anxietyrelated traits with a polymorphism in the serotonin transporter gene regulatory region. Science 274:1527-1531.

Meyer JH (2007) Imaging the serotonin transporter during major depressive disorder and antidepressant treatment. J Psychiatry Neurosci 32:86-102.

Mikheenko Y, Shiba Y, Sawiak S, Braesicke K, Cockcroft G, Clarke H, Roberts AC (2015) Serotonergic, brain volume and attentional correlates of trait anxiety in primates. Neuropsychopharmacology 40:1395-1404.

Nikolova YS, Koenen KC, Galea S, Wang C-M, Seney ML, Sibille E, Williamson DE, Hariri AR (2014) Beyond genotype: serotonin transporter epigenetic modification predicts human brain function. Nat Neurosci 17:1153-1155.

Oikonomidis L, Santangelo AM, Shiba Y, Clarke FH, Robbins TW, Roberts AC (2017) A dimensional approach to modeling symptoms of neuropsychiatric disorders in the marmoset monkey. Dev Neurobiol 77:328-353.

Oler JA, Fox AS, Shelton SE, Christian BT, Murali D, Oakes TR, Davidson RJ, Kalin NH (2009) Serotonin transporter availability in the amygdala and bed nucleus of the stria terminalis predicts anxious temperament and brain glucose metabolic activity. J Neurosci 29:9961-9966.

Pezawas L, Meyer-Lindenberg A, Drabant EM, Verchinski B. a, Munoz KE, Kolachana BS, Egan MF, Mattay VS, Hariri AR, Weinberger DR (2005) 5-HTTLPR polymorphism impacts human cingulate-amygdala interactions: a genetic susceptibility mechanism for depression. Nat Neurosci 8:828-834.

Prater KE, Hosanagar A, Klumpp H, Angstadt M, Luan Phan K (2013) Aberrant amygdala-frontal cortex connectivity during perception of fearful faces and at rest in generalized social anxiety disorder. Depress Anxiety 30:234-241.

Quah SKL, Cockcroft GJ, McIver L, Santangelo AM, Roberts AC (2020) Avoidant Coping Style to High Imminence Threat Is Linked to Higher Anxiety-Like Behavior. Front Behav Neurosci 14:34.

Rainnie DG (1999) Serotonergic modulation of neurotransmission in the rat basolateral amygdala. J Neurophysiol 82:69-85.

Rhodes RA, Murthy NV Dresner MA Selvaraj S, Stavrakakis N, Babar S, Cowen PJ, Grasby PM (2007) Human 5-HT transporter availability predicts amygdala reactivity in vivo. J Neurosci 27:9233-9237.

Roberts A (2020) Prefrontal regulation of threat-elicited behaviors: a pathway to translation. Annu Rev Psychol 71:357-387.

Santangelo AM, Ito M, Shiba Y, Clarke HF, Schut EH, Cockcroft G, Ferguson-Smith AC, Roberts AC (2016) Novel primate model of 
serotonin transporter genetic polymorphisms associated with gene expression, anxiety and sensitivity to antidepressants. Neuropsychopharmacol 41:2366-2376.

Schnell CR, Wood JM (1993) Measurement of blood pressure and heart rate by telemetry in conscious, unrestrained marmosets. Am J Physiol 264: H1509-H1516.

Shiba Y, Santangelo AM, Braesicke K, Agustín-Pavón C, Cockcroft G, Haggard M, Roberts AC (2014) Individual differences in behavioral and cardiovascular reactivity to emotive stimuli and their relationship to cognitive flexibility in a primate model of trait anxiety. Front Behav Neurosci 8:137.

Shiba Y, Santangelo AM, Roberts AC (2016) Beyond the medial regions of prefrontal cortex in the regulation of fear and anxiety. Front Syst Neurosci 10:12.

Shiba Y, Oikonomidis L, Sawiak S, Fryer TD, Hong YT, Cockcroft G, Santangelo AM, Roberts AC (2017) Converging prefronto-insula-amygdala pathways in negative emotion regulation in marmoset monkeys. Biol Psychiatry 82:895-903.

Shimamoto Y, Kitamura H, Niimi K, Yoshikawa Y, Hoshi F, Ishizuka M, Takahashi E (2013) Selection of suitable reference genes for mRNA quantification studies using common marmoset tissues. Mol Biol Rep 40:6747-6755.

Shin LM, Liberzon I (2010) The neurocircuitry of fear, stress and anxiety disorders. Neuropsychopharmacology 35:169-191.

Sinclair LI, Christmas DM, Hood SD, Potokar JP, Robertson A, Isaac A, Srivastava S, Nutt DJ, Davies SJC (2009) Antidepressant-induced jitteriness/anxiety syndrome: systematic review. Br J Psychiatry 194:483-490.

Steiger JH (1980) Tests for comparing elements of a correlation matrix. Psychol Bull 87:245-251.
Steimer T (2002) The biology of fear- and anxiety-related behaviors. Dialogues Clin Neurosci 4:231-249.

Stein MB, Seedat S, Gelernter J (2006) Serotonin transporter gene promoter polymorphism predicts SSRI response in generalized social anxiety disorder. Psychopharmacology (Berl) 187:68-72

Stevens JP (1992) Applied multivariate statistics for the social sciences. Hillsdale: Lawrence Erlbaum Associates.

Wager TD, Phan KL, Liberzon I, Taylor SF (2003) Valence, gender, and lateralization of functional brain anatomy in emotion: a meta-analysis of findings from neuroimaging. Neuroimage 19:513-531.

Wallis CU, Cardinal RN, Alexander L, Roberts AC, Clarke HF (2017) Opposing roles of primate areas 25 and 32 and their putative rodent homologs in the regulation of negative emotion. Proc Natl Acad Sci USA 114:E4075-E4084.

Weger M, Sandi C (2018) High anxiety trait: a vulnerable phenotype for stress-induced depression. Neurosci Biobehav Rev 87:27-37.

Yokoyama C, Kaiya H, Kumano H, Kinou M, Umekage T, Yasuda S, Takei K, Nishikawa M, Sasaki T, Nishimura Y, Hara N, Inoue K, Kaneko Y, Suzuki S, Tanii H, Okada M, Okazaki Y (2015) Dysfunction of ventrolateral prefrontal cortex underlying social anxiety disorder: a multi-channel NIRS study. Neuroimage Clin 8:455-461.

Younts TJ, Monday HR, Dudok B, Klein ME, Jordan BA, Katona I, Castillo $\mathrm{PE}$ (2016) Presynaptic protein synthesis is required for long-term plasticity of GABA release. Neuron 92:479-492.

Zeredo JL, Quah SKL, Wallis CU, Alexander L, Cockcroft GJ, Santangelo AM, Xia J, Shiba Y, Dalley JW, Cardinal RN, Roberts AC, Clarke HF (2019) Glutamate within the marmoset anterior hippocampus interacts with area 25 to regulate the behavioral and cardiovascular correlates of high-trait anxiety. J Neurosci 39:3094-3107. 